This paper was published in the journal Cartography

Visit http://www.mappingsciences.org.au/journal.htm for more information.

Full reference:

Hickey, R., 2000, Slope Angle and Slope Length Solutions for GIS. Cartography, v. 29, no. 1, pp. $1-8$.

\title{
Slope Angle and Slope Length Solutions for GIS
}

\author{
Robert Hickey \\ School of Spatial Sciences \\ Curtin University of Technology \\ GPO Box U 1987 \\ Perth 6001, Western Australia \\ rhickey@vesta.curtin.edu.au
}

\begin{abstract}
The Universal Soil Loss Equation has been used for a number of years to estimate soil erosion. One of its parameters is slope length, however, slope length has traditionally been estimated for large areas rather than calculated. Using data from regular grid DEMs, a method is described in this paper for calculating the cumulative downhill slope length. In addition, methods for calculating slope angle and downhill direction (aspect) are defined. Details of the algorithm and its associated advantages and disadvantages are discussed.
\end{abstract}

\section{INTRODUCTION}

Slope angle and slope length calculations are an integral part of many environmental analyses, particularly erosion models. Unfortunately, there are problems with most of the methods currently available for the calculation of these parameters.

Typical slope angle computation methods calculate an average slope based upon, roughly, a 3x3 neighbourhood (Fairfield and Leymarie 1991). The maximum slope method calculates the maximum angle to or from the centre cell - the result of this being much higher overall slope angle estimates (and resulting erosion estimates). The proposed solution to these 
problems (averaging or overestimating) is to calculate maximum downhill slope angle constraining the slope angle calculations to one cell length (or 1.4 cell lengths in the diagonal) in a downhill direction. This slope angle also corresponds to the direction of overland flow from the cell in question. For more information regarding different slope angle calculations, see Dunn and Hickey (1998) and Srinivasan and Engel (1991).

Slope length calculations are often the most problematic of the erosion model parameters. The traditional method of calculation has been to use a regional estimate - thereby converting a variable into a constant (Troeh, et al., 1991). Most recent work has centred around using either unit stream power (Moore and Burch, 1986) or upslope area (Desmet and Govers, 1996) as a surrogate for slope length. The methodology described in this paper involves calculating slope length from high points (ridges/peaks) along the direction of maximum downhill slope angle (flowdirection). Converging flows and areas of deposition are accounted for in the algorithm.

\section{EROSION MODELLING USING THE USLE}

The Universal Soil Loss Equation (USLE) has been used for a number of years to predict soil erosion rates. In its traditional form, the USLE is given by the following equation (Wischmeier and Smith, 1978):

\section{$\mathbf{A}=\mathbf{R}$ K L S C P}

Where $A$ is the average annual soil loss per unit area

$R$ is the rainfall and runoff factor

$K$ is the soil erodability factor

$L$ is the slope length factor

$S$ is the slope steepness factor

$C$ is the cover and management factor

$P$ is the support practice factor

The L and S factors are commonly combined as LS and referred to as the Slope factor (Troeh, et a.l, 1991). This paper will focus on generating the $\mathrm{L}$ and $\mathrm{S}$ factors from a digital elevation model (DEM) within a GIS. The two inputs to the LS factor are cumulative slope length and slope angle. 
In recent years, soil erosion models more advanced than the USLE have been developed, including ANSWERS (Beasley and Huggins, 1991), AGNPS (Young et al., 1987), WEPP (Laflen et al., 1991; Savabi, et al., 1995), and the USLE's replacement, RUSLE (Renard et al., 1997; Renard et al., 1991). It is important to note that all models include a slope component and that the RUSLE, WEPP, and AGNPS models include a slope length component in their equations.

\section{METHODS OF SLOPE ANGLE CALCULATION}

Calculating slope from a DEM is relatively simple, but care must be taken when selecting an algorithm. For example, the ARC/INFO GRID command, SLOPE, uses the quadratic surface algorithm by Srinivasan and Engel (1991) (ESRI, 1997); IDRISI's algorithm calculates maximum slope, but only considers the four cardinal directions (N S E W) from a $3 \times 3$ neighbourhood (IDRISI, 1997). Other available algorithms include the neighbourhood method and the best fit plane method (Srinivasan and Engel, 1991). These, along with the quadratic surface method, examine the neighbourhood around an elevation cell and determine the slope across the cell in question based upon at least four of the neighbour cells. As such, all three calculate an average slope based upon, roughly, a 3x3 neighbourhood. The maximum slope method calculates the maximum angle to or from the centre cell - the result of this being much higher overall slope angle estimates (and resulting erosion estimates) (Srinivasan and Engel, 1991; Srinivasan, et al., 1994; Dunn and Hickey, 1997).

Given the limitations in the above methods (averages across a 3x3 neighbourhood, maximum values, and only using cardinal directions), a compromise method was required to retain local variability without focusing entirely on maximum slope angles.

This method is the maximum downhill slope angle which constrains the slope angle calculations to one cell length (or 1.4 cell lengths in the diagonal) in a downhill direction. It is similar to the maximum slope method, but it includes a directional component -- angles are constrained to a downhill direction (uphill angles are calculated as having a negative slope). The obvious limitation with this method is negative slope angles are produced when dealing with depressions in a DEM. A side benefit is that the slope angle also corresponds to the direction of overland flow from the cell in question (Dunn and Hickey, 1997).

Computer code to calculate maximum downhill slope angle (and cumulative downhill 
slope length) are available for both Arc Info (AML format) and IDRISI (executable code). They can be downloaded from http://www.cage.curtin.edu.au/ rhickey/slope.html and are free.

\section{METHODS OF SLOPE LENGTH CALCULATION}

Generating the LS values poses the largest problem in using the USLE (Griffin et al., 1988; Moore and Wilson, 1992; Renard, et. al., 1991), especially when applying it to real landscapes within a GIS (Griffin et al., 1988). Traditionally, the best estimates for L are obtained from field measurements, but these are rarely available or practical. Unfortunately, because of the lack of detailed slope length measurements or reliable software algorithms, regional average slope length values are often used (Cowen, 1993) - thereby treating a variable as a constant.

The particular algorithms that have been developed to calculate slope length include gridbased methods (Hickey et al., 1994; Hickey, 1994), unit stream power theory (Mitasova, 1993; Mitasova, et al., 1996, Moore and Wilson, 1992; Moore and Burch, 1986), contributing area (Desmet and Govers, 1995; Desmet and Govers, 1996), and Cowen's (1993) study which developed the means to calculate cumulative downhill slope length from a TIN (triangular irregular network) within ARC/INFO.

\section{GRID-BASED ALGORITHM DESCRIPTION:}

The overall methodology for calculating the $\mathrm{L}$ and $\mathrm{S}$ factors is illustrated in Figure 1. The first requirement for the algorithm is a DEM, preferably a depressionless DEM. This is suggested for two reasons. First, true depressions are rare in nature, as such, depressions in DEMs are often errors. Second, when using the suggested maximum downhill slope angle algorithm, depressions will return negative slope values. This will eventually result in negative erosion estimates (deposition). AML code is available for ARC/INFO which eliminates all depressions (the FILL command in ARC/INFO GRID does not eliminate all depressions), unfortunately, no similar code is available for IDRISI.

Once this has been completed, the maximum downhill slope and the flowdirection are calculated from the DEM. It is important to note here that the flowdirection and the direction of maximum downhill slope are the same.

High points (local maxima) are designated by selecting those cells which have either no 
flow entering them or in cases where both the cell in question and its input cell have a slope angle of zero. For accurate cumulative slope length values, the high points calculated by the model must correspond to true terrain high points. From a geomorphic perspective, these primarily include ridges and peaks, however, there are often other parts of the landscape that do not receive flow from upslope. To accomplish the identification of high points, the model must be run on hydrologically isolated areas (ie. watershed scale, not on partial watersheds). If this is not done, slope lengths are underestimated because the high points calculated may be located on the sides of slopes, not on ridgelines.

Non-cumulative slope length (NCSL) is then calculated for each cell within the watershed. In short, the distance to each cell from its input cell is calculated using the following equations:

if the cell being calculated is a high point

$$
\text { then } \quad \mathrm{NCSL}=0.5 \text { (cell resolution) }
$$

if the input cell is in a cardinal direction $(\mathrm{N}, \mathrm{S}, \mathrm{E}, \mathrm{W})$,

$$
\text { then } \quad \mathrm{NCSL}=(\text { cell resolution })
$$

otherwise,

$$
\text { NCSL }=1.4142(\text { cell resolution) }
$$

This calculation is based on the assumption that the calculations for slope length are from the centre of the cell to the center of its input cell. Therefore, as high points do not have an input cell, the 0.5 value represents only the erosion occurring within the half of that cell that is uphill of the centre point. The measurements are done within $(\mathrm{x}, \mathrm{y})$ space rather than $(\mathrm{x}, \mathrm{y}, \mathrm{z})$ space to conform to USLE and RUSLE input requirements (Renard, et al., 1997).

At this point, all the required input grids are present in order to calculate the cumulative slope length (ie NCSL, slope angle, high points and flowdirection). Curriculum slope length is computed by simply summing the non-cumulative slope lengths along the flow direction beginning at the high points.

There are a number of assumptions built into this calculation. The first is that in areas of converging flows, the highest cumulative slope length takes precedence. The second assumption to be considered is for areas where deposition, not erosion, is the dominant process. As such, the 
code includes a mechanism for defining areas of deposition (useful when calculating erosion), called the cutoff slope angle. When considering water flowing across the earth's surface carrying sediment, the flow velocity will decrease enough at some points so that the sediment carried will be deposited - rather than the energy of the flow enabling more sediment (erosion) to be picked up. The critical factor is to define those parts of the landscape where this will happen. The answer is primarily a function of two things: the slope of the land (which very much defines the velocity), and the saturation of the flow. If the flow is fully saturated (with sediment), any decrease in velocity will result in deposition rather than erosion. On the other hand, if the flow is relatively unsaturated, it will take a very significant decrease in slope (possibly to zero) to result in deposition.

This particular problems is addressed by the cutoff slope angle which is a user-input value. The cutoff slope angle is defined as the change in slope angle from one cell to the next along the flowdirection. This value ranges from 0 to 1 for all areas where the slope angle decreases from one cell to the next (if the slope angle increases, there will definitely be no deposition). Therefore, the user input value will range from $0-1$ and be dependent upon the amount of sediment carried by overland flow. For example, an input value of zero will cause the slope length to reset every time there is a decrease in slope angle. An input value of one will cause the slope length to never reset. In an ideal world, this value would be set by an expert familiar with the particular area in question. However, this is not always feasible. The literature (Griffin, et al., 1988; Wilson, 1986) suggests references that a value closer to 0.5 (slope decreasing by $50 \%$ or greater) is appropriate. This is similar to assumptions made in other studies (Griffin, et al., 1988; Wilson, 1986), although in these cases, the cutoffs were a change of $50 \%$ from the average uphill slope angle and a change of 50\% from the maximum uphill slope angle, respectively. It is important to note that the algorithms described in this paper only consider the nearest upslope cell in the cutoff calculations - not an average upslope or maximum uphill slope angle. However, the program does allow the user to specify any cutoff value.

The final steps in this analysis are to convert the cumulative slope length values into feet (if necessary) and to calculate the LS values. The USLE equation for LS values is:

$$
\mathrm{LS}=(\ell / 72.6)^{\mathrm{m}}\left(65.41 \sin ^{2} \beta+4.56 \sin \beta+0.065\right)
$$

where $\mathrm{\ell}$ is the cumulative slope length in feet; 
$\beta$ is the downhill slope angle;

$m$ is a slope contingent variable;

0.5 if the slope angle is greater than $2.86^{\circ}, 0.4$ on slopes of $1.72^{\circ}$ to $2.86^{\circ}$;

0.3 on slopes of $0.57^{\circ}$ to $1.72^{\circ}$;

0.2 on slopes less than $0.57^{\circ}$ (Wischmeier and Smith, 1978).

The ARC/INFO AML program that calculates the LS values requires a DEM coverage and two input values: the cell resolution units (feet or metres) and the cutoff slope angle required for identifying cells with net deposition rather than erosion (a $50 \%$ decrease is the default). The IDRISI executable is run from a DOS window and requires the input of the DEM filename, output filenames, and the cutoff slope angle (no default given). The final outputs from the AML are three coverages: ls_values (USLE LS values), slope_angle (downhill slope angles), and slope_len (the cumulative slope lengths). The IDRISI code outputs the following: maximum downhill slope angle, non-cumulative slope length, cumulative downhill slope length, and the flowdirection. In this case, all filenames are input by the user.

Figure 2 illustrates the results of the calculation on a $5 \times 5$ test grid. The DEM (Figure 2a) is relatively small and has a 100 metres resolution - designed for easy understanding of the results of the code. The cumulative downhill slope length is shown in Figure 2e using a cutoff slope of 0.5. For comparison, Figure 2e also shows the result of using different slope cutoff values of 0.25. At a cutoff slope angle of 0.5, two slope lengths are reset to zero; when the cutoff slope angle is set to 0.25 , the changes in slope are not enough to reset the cumulative slope lengths to zero.

\section{DEM PROBLEMS AND LIMITATIONS:}

It is important to note that there are a number of problems unique to DEMs that need to be addressed, as all may impact upon slope angle and slope length calculations.

- The first involves the many depressions (or pits) that are common on DEMs (Quinn et al. 1991). Real or not, in all cases they will interrupt the flow of water downhill (according to the GIS). The slope length algorithm recognises these cells as areas of deposition and resets the slope length to zero.

- The second problem is associated with striping; systematic errors that give parts of 
the map a boxy appearance. These are errors in the DEM that are often a result of the DEM creation process and will cause errors in any DEM-based analysis.

- Third is the typically low resolution of DEMS (ie. 30m for 7.5 minute USGS DEMs). Microfeatures which slow (or increase) runoff, and therefore erosion, are lost. Thus, erosion estimates will be in error. As DEM resolution and accuracy increase, the landscape will be more accurately described and erosion estimates will approach actual values.

- Finally, there are often problems when joining two separate DEMs. For example, joining two DEMs may result in a apparent cliff running across the map.

In many cases, these problems cannot be averted without re-creating the DEM - either via photogrammetric methods or digitizing existing large scale contour maps. Therefore, DEM users must be aware of potential errors in their datasets and consider the results of these errors in their final products (maps, reports, etc.). See Fahsi, et al. (1990) for more details concerning the formation of and problems associated with DEMs.

\section{MODEL ADVANTAGES}

The maximum downhill slope angle calculations have the following advantages:

- By considering slope angle as a function of only two cells, the local variability is retained (no averaging across 3 cells).

- The maximising effects of the maximum slope angle calculation method are reduced by constraining slope angles to the downhill direction.

To avoid using regional averages for slope length calculations, cumulative slope length calculations are the only practical alternative if erosion rates are to be modelled. The advantages of the grid-based model are:

- The algorithm considers both areas of deposition and converging flows when calculating cumulative downhill slope length. When passed through the LS calculations, those areas in which cumulative slope length is set to zero will have a zero value for LS -- which results in a zero value for erosion.

- The cumulative slope length output can be used in a number of different erosion models, including the USLE, RUSLE, and AGNPS (Wischmeier and 
Smith, 1978; Renard, et al., 1991; Young, et al., 1987).

- The erosion rates coverage can be used within the GIS as an input to land suitability analysis problems. For example, erosion rates may be one factor considered when deciding which parts of a large, environmentally damaged site should be reclaimed (Hickey, 1994; Hickey, et al., 1997).

- Erosion rates can be calculated for large areas without time-consuming and costly slope length field surveys.

\section{SUMMARY}

Due to limitations in memory, calculation speed and availability of data, hydrologic modelling is limited to using DEMs with relatively coarse resolutions. Most microfeatures are lost with cell lengths greater than 5 metres and most models attempt to average data across three neighbouring cells which is 90 metres on a standard one second DEM (Haddock, 1996). Also, other models may calculate the slope length using a maximum difference in a $3 \times 3$ neighbourhood with the effect that this approach tends to exaggerate the slope lengths of the individual cells.

The model described in this paper provides an alternative to some of these shortcomings by calculating the cumulative uphill length from each cell which also accounts for convergent flow paths and depositional areas. Using the Slope Length model, more accurate slope length predictions can be assessed for use in the Universal Soil Loss Equation and other hydrologic models. 


\section{References}

Beasley, D.B. and Huggins, L.F. (1991) ANSWERS users manual: Department of Agr. Eng., Purdue Univ., West Lafayette, IN.

Cowen, J. (1993) A proposed method for calculating the LS factor for use with the USLE in a grid-based environment: Proceedings of the thirteenth annual ESRI user conference, pp. $65-74$.

Desmet, P. and Grovers, G. (1995) GIS-based simulation of erosion and deposition patterns in an agricultural landscape: a comparison of model results with soil map information. Catena, 25, 389 - 401.

Desmet, P. and Grovers, G. (1996) A GIS procedure for automatically calculating the USLE LS factor on topographically complex landscape units. Journal of Soil and Water Conservation, 51(5), $427-433$.

Dunn, M. and Hickey, R. (1998) The Effect of Slope Algorithms on Slope Estimates within a GIS. Cartography, v. 27, no. 1, pp. $9-15$.

Environmental Systems Research Institute (ESRI) (1997) Arc/Info, version 7.2, Online Users Guide.

Fahsi, A., Ulliman, J. and Chang, K. (1990) The effects of the source of digital elevation models on contour map accuracy: GIS/LIS'90 Proceedings, Anaheim CA, 1, 335-344.

Fairfield, J. and Leymarie, P. (1991) Drainage networks from grid Digital Elevation Models. Water Resources Research, 27(5), 709-717.

Griffin, M.L., Beasley, D.B., Fletcher, J.J and Foster, G.R. (1988) Estimating soil loss on topographically nonuniform field and farm units. Journal of Soil and Water Conservation, 43, 326-331.

Haddock, G. (1996) VEEGRID: a visual programming environment for spatial modeling. Doctoral Dissertation. Department of Geography, University of Idaho.

Hickey, R. (1994) Design and simulation of smelter reclamation strategies using an environmental decisions support system. Doctoral Dissertation. Department of Geography, University of Idaho.

Hickey, R., Smith, A. and Jankowski, P. (1994) Slope length calculations from a DEM within Arc/Info GRID. Computers, Environment, and Urban Systems, 18(5), 365 - 380.

Hickey, R. and Jankowski, P. (1997) GIS and environmental decision-making to aid smelter reclamation planning: Environment and Planning A., 29, 5 - 19. 
IDRISI (1997) IDRISI, version 2.0 for Windows User's Guide.

Laflen, Lane, J.L. and Foster, G (1991) WEPP: a new generation of erosion prediction technology. Journal of Soil and Water Conservation. Jan/Feb issue: 34 - 38.

Mitasova, H. (1993) Surfaces and Modeling. Grassclippings, 7(1), 18 - 19.

Mitasova, H., Hofierka, J., Zlocha, M. and Iverson, L. (1996) Modelling topographic potential for erosion and deposition using GIS. International Journal of GIS, 10(5), 629 - 641.

Moore, I.D. and Wilson, J.P. (1992) Length-slope factors for the revised universal soil loss equation: simplified method of estimation. Journal of Soil and Water Conservation, 47(5), 423-428.

Moore, I. and Burch, G. (1986) Physical basis of the length-slope factor in the Universal Soil Loss Equation. Soil Society of America Journal, 50, 1294 - 1298.

Quinn, P., Bevin, K., Chevalleir, P. and Planchon, O. (1991) The prediction of hillslope flow paths for distributed hydrological modelling using digital terrain models. Hydrological Processes, 5, 59-79.

Renard, K., Foster, G.R., Weesies, G.A. Porter, J.P. (1991) RUSLE Revised universal soil loss equation. Journal of Soil and Water Conservation, 46, 30-33.

Renard, K., Foster, G., Weesies, G., McCool, D. and Yoder, D. (1997) Predicting soil erosion by water: a guide to conservation planning with the Revised Universal Soil Loss Equation (RUSLE). USDA Agriculture Handbook \#703, 384 p.

Savabi, M., Flanagan, D., Hebel, B., and Engel, B. (1995) Application of WEPP and GISGRASS to a small watershed in Indiana. Journal of Soil and Water Conservation, 50(5), $477-484$.

Srinivasan, R., Engel, B.A., Wright, J.R., Lee, J.G. Jones, D.D. (1994) The impact of GISderived topographic attributes on the simulation of erosion using AGNPS. Applied Engineering in Agriculture, 10(4), 561-566.

Srinivasan, R. and Engel, B.A. (1991) Effect of slope prediction methods on slope and erosion estimates. Applied Engineering in Agriculture, 7(6), 779 - 783.

Troeh, F.R., Hobbs, J.A. and Donahue, R.L. (1991) “Chapter Six: Predicting Soil Loss” Soil and Water Conservation, $2^{\text {nd }}$ ed. Prentice-Hall, Englewood Cliffs, New Jersey, USA.

Wilson, J.P. (1986) Estimating the topographic factor in the universal soil loss equation for watersheds. Journal of Soil and Water Conservation, 41, 179-184. 
Wischmeier, W.H. and Smith, D.D. (1978) Predicting rainfall erosion losses-- $A$ guide to conservation planning: Agricultural Handbook no. 537, Sci. and Educ. Admin., U.S. Dept. Agr., Washington, D.C.

Young, R.A., Ontsad, C.A., Bosch, D.D. and Anderson, W.P. (1987) AGNPS, Agricultural non-Point-Source Pollution Model. A Watershed Analysis Tool. U.S. Department of Agriculture, Conservation Research Report 35, 80 p. 


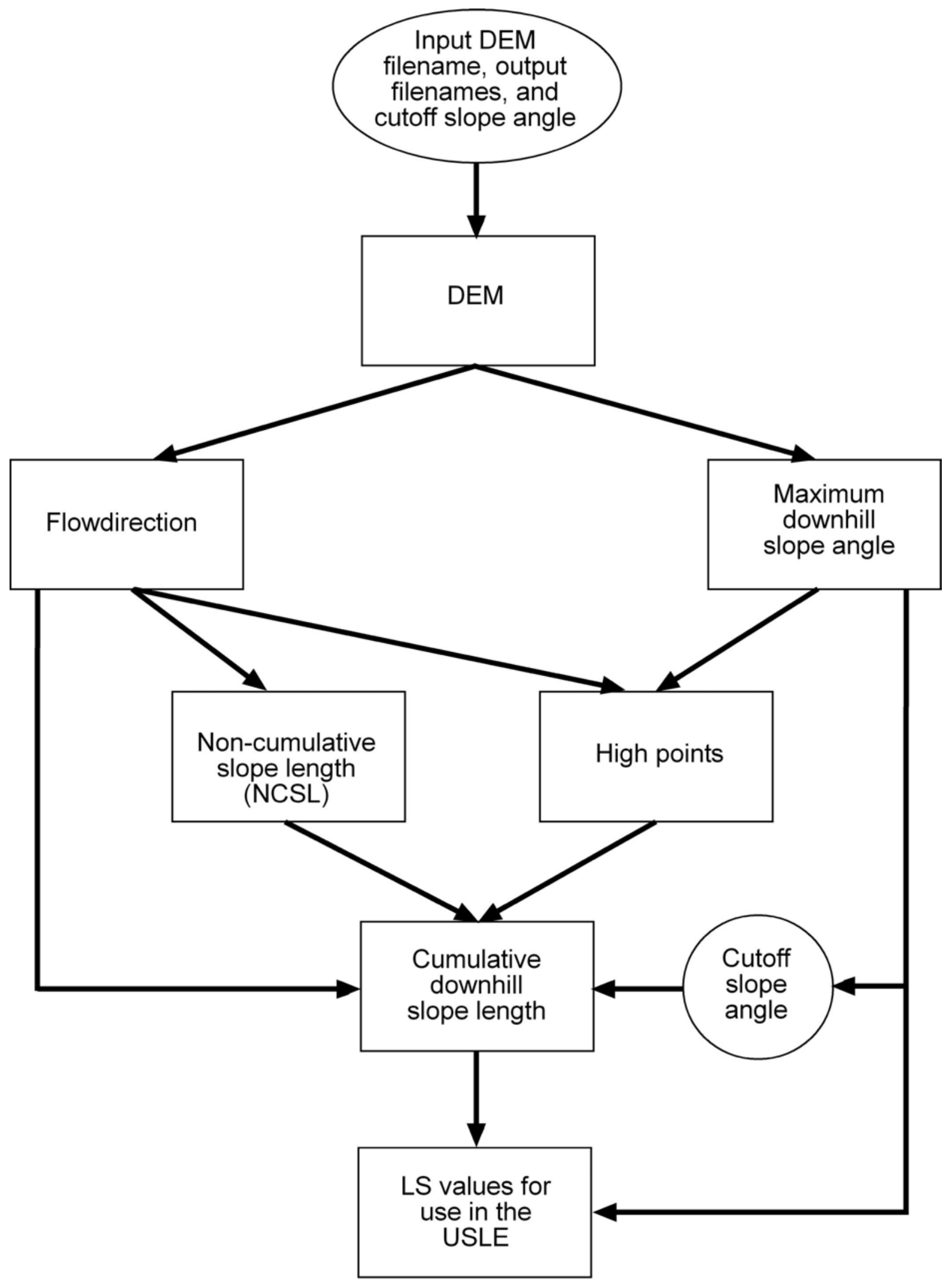

Figure 1. Flowchart illustrating the process of calculating cumulative downhill slope length (and LS values) for use in the USLE. 


\begin{tabular}{|c|c|c|c|c|}
\hline 150 & 125 & 125 & 135 & 150 \\
\hline 125 & 115 & 175 & 130 & 135 \\
\hline 120 & 110 & 100 & 115 & 120 \\
\hline 115 & 100 & 90 & 100 & 130 \\
\hline 105 & 95 & 80 & 90 & 120 \\
\hline
\end{tabular}

Figure 2a

\begin{tabular}{|r|r|r|r|r|}
\hline 14.04 & 5.71 & 4.04 & 5.71 & 8.53 \\
\hline 6.05 & 6.05 & 36.87 & 11.98 & 8.53 \\
\hline 8.05 & 8.05 & 5.71 & 10.02 & 8.05 \\
\hline 8.53 & 8.05 & 5.71 & 8.05 & 16.70 \\
\hline 5.71 & 8.53 & 0 & 5.71 & 16.70 \\
\hline
\end{tabular}

Figure 2c

\begin{tabular}{|c|c|c|c|c|}
\hline 50 & $\begin{array}{c}0 \\
\left({ }^{*} 150\right)\end{array}$ & 291 & 150 & 50 \\
\hline 71 & 432 & 50 & 71 & 50 \\
\hline 71 & 212 & 532 & 71 & 191 \\
\hline 50 & 212 & 632 & 332 & 50 \\
\hline 50 & 150 & 0 & $\begin{array}{c}0 \\
(* 150)\end{array}$ & 50 \\
\hline
\end{tabular}

Figure 2e

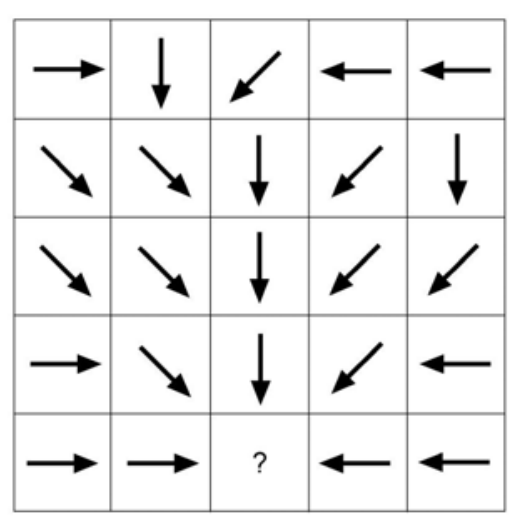

Figure 2b

\begin{tabular}{|r|r|r|r|r|}
\hline 50 & 100 & 141 & 100 & 50 \\
\hline 71 & 141 & 50 & 71 & 50 \\
\hline 71 & 141 & 100 & 71 & 141 \\
\hline 50 & 141 & 100 & 141 & 50 \\
\hline 50 & 100 & 0 & 100 & 50 \\
\hline
\end{tabular}

Figure 2d

Fure 2d

Figure $2 b$

. 